\title{
To what extent could acute general psychiatric day care reduce inpatient admissions?
}

\author{
Thomas W. Kallert ${ }^{1,2,3}{ }^{3}$, Andrea Howardová ${ }^{4}$, Jiri Raboch ${ }^{4}$, Stefan Priebe ${ }^{5}$, Andrzej Kiejna ${ }^{6}$, Pětr \\ Nawka7, Matthias Schützwohl ${ }^{3}$ \\ 1. Department of Psychiatry, Psychosomatic Medicine and Psychotherapy, Park Hospital Leipzig, Leipzig, Germany. \\ 2. Soteria Hospital Leipzig, Leipzig, Germany. 3. Department of Psychiatry and Psychotherapy, University Hospital, \\ Dresden University of Technology, Dresden, Germany. 4. Department of Psychiatry, First Medical Faculty, Charles \\ University of Prague, Prague, Czech Republic. 5. Unit for Social and Community Psychiatry, Barts' and London School of \\ Medicine, London, United Kingdom. 6. Department of Psychiatry, Wrocław University of Medicine, Wrocław, Poland. 7. \\ Michalovce Psychiatric Hospital, Michalovce, Slovak Republic
}

Correspondence: Thomas W. Kallert. Address: Department of Psychiatry, Psychosomatic Medicine and Psychotherapy, Park Hospital Leipzig, Morawitzstraße 2, D-04289 Leipzig, Germany. E-mail: thomas.kallert@parkkrankenhaus-leipzig.de

Received: October 19, 2012

Accepted: January 16, 2013

Online Published: January 24, 2013

DOI: $10.5430 /$ jha.v2n2p105

URL: http://dx.doi.org/10.5430/jha.v2n2p105

\section{Abstract}

Background: Percentage reduction of inpatient admissions by acute general psychiatric day care in individual facilities (i.e. feasibility rate of acute day care) seems to be an important parameter for service planning. Previously reported feasibility rates showed significant variation, however, and were based on eligibility criteria defined for randomized controlled trials. This paper aims to perform an in-depth exploration of the calculation method of these feasibility rates, to propose different calculation methods expanding research definitions to the reality of service provision, and to analyze the association between the availability of residential services in regional mental health service systems and these rates.

Methods: Data from the randomization process of the European Day Hospital Evaluation (EDEN) study in which a total of 1117 patients were included in five sites provided the basis to calculate site-specific and overall rates of patients for whom this mode of treatment might be adequate. Sensitivity analyses were carried out by varying the selection of patients' eligibility criteria and thus calculating different feasibility estimates. Data on the regional mental health care systems were collected by use of the European Service Mapping Schedule.

Results: The use of four different calculation methods showed that site-specific feasibility rates of acute day care for general psychiatric patients varied from $13.8 \%$ to $25.7 \%$ up to $44.1 \%$ to $79.0 \%$. Overall rates varied from $17.3 \%$ up to $67.7 \%$, respectively. The high values were calculated under a scenario where the current acute day care model of care is enhanced to manage more complicated patients than currently treated under existing acute day care models. In three out of the four calculation methods higher rates were calculated for sites which demonstrated higher figures of residential services, and thus were less advanced in their process of deinstitutionalization.

Conclusions: In order to determine the capacity of day hospitals as an alternative to acute psychiatric hospital care, mental health care planning must clearly decide on the eligibility criteria of patients to be treated in these facilities. Guided by such definitions, treatment concepts and professional qualifications of the staff in these facilities need to be adapted. The finding that less de-institutionalized regions may benefit most from a transition to acute day care as a means for promoting the transition to a community model of care for otherwise institutionalized patients must be assessed in more detail. 
Comprehensive research exploring the impact of all regional mental health service configuration characteristics on the concept of acute day care is needed.

\section{Key words}

Acute general psychiatric day care, Eligibility criteria, Feasibility rates, Mental health care planning

\section{Background}

Within the process of restructuring and shortening acute psychiatric inpatient care, several community-oriented alternatives for providing equivalent treatment have been conceptually established and implemented ${ }^{[1]}$. Recent research results support acute day care as the most important of these alternatives.

The first multi-site international randomized controlled trial (RCT) on this subject, the European Day Hospital Evaluation (EDEN) study, demonstrated that day hospital care was as effective as conventional inpatient care with respect to psychopathological symptoms, treatment satisfaction, and quality of life. It was more effective on social functioning at discharge and at the 3- and 12-month follow-up assessments. The core principle of day hospital treatment that allows patients to remain rooted in their normal surroundings and social roles during the acute crisis rather than keeping them day and night on an inpatient ward may explain this outcome ${ }^{[2]}$.

International survey findings on the characteristics of day hospitals for general psychiatric patients in the five European countries studied show that the applicability of such results on the national service level differs significantly. Because of the similarity of organizational features and of the patient populations in the EDEN centres, results might be relevant for $39 \%$ to $49 \%$ of day hospital services in the two Western European countries (Germany, and England), but for only $7 \%$ to $32 \%$ of these services in the three Central European countries (Poland, Czech and Slovak Republics) ${ }^{[3]}$.

Apart from the question of applicability of RCT results to service level, the feasibility of acute day care seems to be the most important parameter for service planning, particularly in times of cost-containment. Several single-site randomized controlled trials showed that day care might reduce direct health care costs within treatment episodes by $21 \%$ to $37 \%$ as compared with conventional inpatient treatment ${ }^{[4-10]}$. Acute day care may therefore offer a cost effective treatment mode that produces equivalent reductions in psychopathology for suitable patients whilst enabling the maintenance of existing social roles and connections that are important for promotion of recovery.

In a Cochrane review on this subject ${ }^{[11]}$ feasibility of acute day care was defined as the percentage reduction in acute inpatient admissions (i.e. feasibility rate) that could be achieved by diverting patients to an acute day hospital. This definition considers neither the availability of day hospital "beds" nor costs associated with creating or re-organizing facilities. Based on patient characteristics defining their eligibility for acute day care, the concept of feasibility rates provides an estimate of the extent to which existing inpatient facilities could be re-structured for providing acute day care. Previous single-site RCTs ${ }^{[4-6,12-17]}$ found feasibility rates within the range of $23 \%$ to $39 \%$, and the EDEN study - whose recruitment more than doubled the RCT database on acute day care of general psychiatric patients - reported an overall feasibility rate of $23.3 \%$, ranging across study sites from $16.6 \%$ to $35.4 \%{ }^{[2]}$.

Although these figures seem to be promising for mental health care planning in the area of hospital care, the question of feasibility rates needs to be assessed in more detail. First, acute general psychiatric day (hospital) care is not a well-defined concept. Definitions mainly focus on general issues such as provision of diagnostic and treatment services for acutely ill patients who would otherwise be treated on traditional psychiatric inpatient units, and on structural elements of service units needed for providing such type of service such as symptoms and history do not require a 24-hour, continuous, structured therapeutic milieu ${ }^{[18]}$. Further, the concept emphasizes that this type of care should be distinguished from other types of day care such as transitional care for patients leaving hospital, more intensive alternatives to outpatient treatment, and support of long-term patients living in the community ${ }^{[3,19]}$. These definitions, however, do not provide detailed 106

ISSN 1927-6990 E-ISSN 1927-7008 
clinical criteria for the patients to be treated in such settings. Second, the reported rates showed significant variation and are based on eligibility criteria defined for research purposes in RCTs, which vary among single-site studies ${ }^{[4-6,}{ }^{12-17]}$. Third, definitions of patients to be treated by acute day care vary even more in routine practice among day hospitals, as demonstrated by the heterogeneous pattern of exclusion criteria for this setting found in several national surveys ${ }^{[3,20-23]}$. Fourth, the association between characteristics of regional mental health service systems and the percentage reduction rates of inpatient admissions which might be possible by providing acute day care for general psychiatric patients has not yet been explored.

Table 1. Varying definition of patients' eligibility criteria as basis for calculating most inclusive ("lowest") and moderately inclusive ("highest") feasibility estimates of acute day care for general psychiatric patients

\begin{tabular}{|c|c|c|c|c|c|}
\hline & $\begin{array}{l}\text { Dresden } \\
\mathbf{N}\end{array}$ & $\begin{array}{l}\text { London } \\
\mathbf{N}\end{array}$ & $\begin{array}{l}\text { Wroclaw } \\
\mathbf{N}\end{array}$ & $\begin{array}{l}\text { Michalovce } \\
\mathbf{N}\end{array}$ & $\begin{array}{l}\text { Prague } \\
\mathbf{N}\end{array}$ \\
\hline Number of patients admitted to hospital & 1,157 & 1,409 & 1,089 & 1,487 & 1,543 \\
\hline Admitted strictly for diagnostic purposes & 77 & 88 & 10 & 35 & 14 \\
\hline Aged $<18$ or $>65$ & 177 & 14 & 103 & 44 & 176 \\
\hline $\begin{array}{l}\text { Number of patients serving as calculation base } \\
\text { for the most inclusive ("lowest”) estimate of } \\
\text { feasibility rates }\end{array}$ & 903 & 1,307 & 976 & 1,408 & 1,353 \\
\hline Involuntary admissions/other legal restrictions ${ }^{\dagger}$ & 98 & 497 & 150 & 70 & 70 \\
\hline One-way journey to hospital $>60$ minutes & 76 & 2 & 100 & 138 & 273 \\
\hline Somatic disorder requiring inpatient care & 36 & 10 & 15 & 19 & 60 \\
\hline Acute intoxication & 8 & 3 & 4 & 8 & 17 \\
\hline $\begin{array}{l}\text { Number of patients serving as calculation base } \\
\text { for the moderately inclusive ("highest") estimate } \\
\text { of feasibility rates }\end{array}$ & 685 & 795 & 707 & 1,173 & 933 \\
\hline Main clinical diagnosis of addictive disorder & 111 & 47 & 63 & 311 & 132 \\
\hline Direct transfer from another hospital & 26 & 15 & 42 & 80 & 62 \\
\hline Homelessness & 9 & 82 & 7 & 13 & 6 \\
\hline Needs constant pick-up and delivery & 3 & 0 & 1 & 9 & 28 \\
\hline $\begin{array}{l}\text { Unable to give informed consent re study } \\
\text { participation }\end{array}$ & 50 & 34 & 95 & 77 & 17 \\
\hline Suicidal risk & 32 & 55 & 23 & 27 & 179 \\
\hline Risk to others & 2 & 42 & 22 & 11 & 37 \\
\hline $\begin{array}{l}\text { Measures to restrict the patient's freedom, or } \\
\text { one-on-one supervision, required or deemed } \\
\text { probable }\end{array}$ & 171 & 69 & $\ldots^{\dagger \dagger}$ & 359 & 212 \\
\hline $\begin{array}{l}\text { Already randomized (i.e. re-admitted during the } \\
\text { recruitment period of the study) }\end{array}$ & 24 & 19 & 18 & 0 & 4 \\
\hline Other reasons for exclusion & 12 & 86 & 59 & 6 & 0 \\
\hline Number of patients asked to participate & 245 & 346 & 377 & 280 & 256 \\
\hline Patients who refused to participate & 45 & 137 & 114 & 45 & 46 \\
\hline Number of recruited and randomized patients & 200 & 209 & 263 & 235 & 210 \\
\hline
\end{tabular}

Thus within regional mental health service systems, as well as in the view of financial carriers like health insurances, it is not clear how many and which types of patients can be treated in acute day hospitals. For mental health care planners, calculating the number of such treatment places really needed within the configuration of mental health service systems remains an unresolved issue. 
Against this background, this paper has three aims: First, it performs a sensitivity analysis of the feasibility rates established in the EDEN-study in which eligibility criteria of patients for this setting were varied from a lowest to a highest estimate. Second, it proposes and explains alternative calculation modes of feasibility rates aiming to cover the reality of re-organizing routine mental health service provision in inpatient facilities. Third, it analyzes the association between the availability of residential services in regional mental health service systems participating in the EDEN-study and these rates.

Table 2. Feasibility of acute day care for general psychiatric patients and site-specific data on the availability of residential services

\begin{tabular}{|c|c|c|c|c|c|c|}
\hline Study site variables & Dresden & London & Wroclaw & Michalovce & Prague & All sites \\
\hline Number of patients asked to participate & 245 & 346 & 377 & 280 & 256 & 1,504 \\
\hline $\begin{array}{l}\text { Number of recruited and randomized } \\
\text { patients }\end{array}$ & 200 & 209 & 263 & 235 & 210 & 1,117 \\
\hline Randomization ratio $(\mathrm{R})$ & 0.48 & 0.69 & 0.49 & 0.53 & 0.49 & 0.53 \\
\hline $\begin{array}{l}\text { Number of patients who received acute } \\
\text { day care }\end{array}$ & 92 & 124 & 123 & 105 & 103 & 547 \\
\hline Method A feasibility rate (\%) & 21.2 & 13.8 & 25.7 & 14.1 & 15.5 & 17.3 \\
\hline Method B feasibility rate (\%) & 28.0 & 22.6 & 35.5 & 17.0 & 22.5 & 23.9 \\
\hline Method C feasibility rate (\%) & 28.2 & 19.2 & 39.4 & 18.8 & 19.3 & 23.7 \\
\hline Method D feasibility rate (\%) & 79.0 & 44.1 & 73.9 & 78.9 & 70.4 & 67.7 \\
\hline $\begin{array}{l}\text { Acute hospital-based residential services } \\
\text { related to a population of } 100,000\end{array}$ & 63.2 & 30.6 & 76.6 & 32.1 & 90.0 & \\
\hline $\begin{array}{l}\text { All residential services related to a } \\
\text { population of } 100,000\end{array}$ & 156.8 & 120.6 & 255.6 & 104.9 & 252.0 & \\
\hline
\end{tabular}

\section{Methods}

Details of the EDEN study design (e.g. characteristics of the treatment settings, randomization procedure, outcome measures) were provided in previous papers ${ }^{[2,24-28]}$, and are not relevant for the analyses presented here. The study was approved by the relevant Research Ethics committees in each country: Ethics Committee at the Faculty of Medicine, Dresden University of Technology, Dresden, Germany; Ethics Committee at the First Medical Faculty, Charles University of Prague, Prague, Czech Republic; Commission of Bioethics at Wroclaw Medical University, Wroclaw, Poland; Ethics Committee at the Hospital of Michalovce, Michalovce, Slovak Republic; East London and The City Research Ethics Committee, London, UK. Of importance for the calculation of feasibility rates were the eligibility and inclusion criteria, which were defined for this international multi-site RCT - carried out in five sites: Dresden, Germany; London, United Kingdom; Wroclaw, Poland; Michalovce, Slovak Republic; Prague, Czech Republic - as follows (see also Table 1): All patients in need of acute admission to a psychiatric facility were eligible to participate. To be included, patients must have presented with a mental disorder with current symptoms that had either led to at least moderate disturbance in performance in more than one area of daily living or had jeopardized the residential, financial, or occupational status of the patient or his/her family. Treatments other than inpatient or day hospital care must have been inadequate or not sufficiently effective for the patient's current mental state ${ }^{[2,18]}$. Main exclusion criteria (see also Table 1) were temporary admission for diagnostic purposes or for other purposes than treatment; age under 18 or over 65 years; involuntary admission; one-way journey to hospital greater than 60 minutes; measures to restrict the patient's freedom, or one-on-one supervision, required or deemed probable; acute intoxication; main diagnosis of addictive disorder; presence of a somatic disorder requiring inpatient care; direct transfer from a different hospital; homelessness; need for constant pick-up and delivery service; and inability to give informed consent. 


\section{Measures}

\section{Calculation of feasibility rates in RCTs on acute general psychiatric day care}

The general feasibility formula - a modification of the method suggested by Kluiter et al. ${ }^{[1,29]}$ - used was $100 \times$ (number of patients engaging in day care)/(number assessed for eligibility $\times \mathrm{R}$ ), where $\mathrm{R}$ represents the randomization ratio for the trial (defined as number randomized to day hospital/number of patients randomized) (see also Table 2).

For calculating the "lowest" (i.e. most inclusive) estimate of feasibility rates (calculation method $\mathrm{A}=(100 \times$ number engaging in acute day care $) /(\mathrm{R} \times$ number assessed for eligibility $)$, only patients admitted strictly for diagnostic purposes/other purposes than for treatment, and patients aged younger than 18 or older than 65 years are excluded from the number assessed for eligibility. This definition is guided by the clinical reality of general psychiatric hospitals that face high demands on service provision and are obliged to admit all patients from their catchment area between 18 and 65 years of age. In method A, the number of eligible patients only excludes those admitted for diagnostic/non-treatment purposes or who are out of age range. Thus, this method is consistent with the "best estimate" definition presented in a Cochrane review on the subject of acute day hospital care ${ }^{[1]}$ for calculating feasibility rates in which only administrative exclusions are made.

To calculate the "highest" (i.e. moderately inclusive) estimate of feasibility rates (calculation method B), the following patient groups were further excluded from the number assessed for eligibility: involuntarily admitted patients/patients with other legal restrictions, patients whose one-way journey to hospital is longer than 60 minutes, patients with a somatic disorder requiring inpatient care, and acutely intoxicated patients. This definition is guided by the rationale that day hospitals often do not have the competences or resources to manage complicated patients and emphasize their community-orientation ${ }^{[3]}$. By lowering the denominator in this way, it is no longer possible, however, to conclude that the calculated "highest" estimate of feasibility rates reflects the number of patients accessing hospital care who could be diverted, as calculation method B is really giving the percentage of uncomplicated hospital treated patients who can be managed in day hospital care.

\section{Calculation of feasibility rates expanding research definitions to the reality of service provision}

The main point of criticism regarding Kluiter's formula could be that the resulting figures of feasibility rates significantly depend on the site-specific number of patients excluded from being defined as eligible for acute day care. From a clinical perspective, it is not fully understandable and is in contrast to the reality of service provision that a lower figure of eligible patients (artificially) produces a higher feasibility rate. Aiming to fill this gap between research definitions and clinical reality, the EDEN-study group presents two alternative proposals.

For calculation method $\mathrm{C}$, a variant to method $\mathrm{A}$, the basic variable for calculating feasibility rates in the numerator of the formula should be defined as one half of the "number of patients asked to participate," a term established in the Consolidated Standards of Reporting Trials ${ }^{[30]}$. This definition reflects the clinical situation that more people can be diverted than when just considering randomized patients. The formula of calculation method $\mathrm{C}$ is as follows: $(100 \times$ number of patients asked to participate $\div 2) /(\mathrm{R} \times$ number assessed for eligibility as for Method $\mathrm{A})$.

Calculation method D $(100 \times$ number assessed as eligible for Method $B \div 2) /(\mathrm{R} \times$ number assessed for eligibility as for Method A) models the possibility that the day hospital care model of care is able to be enhanced to effectively treat the complicated patients (e.g., intoxicated, involuntary patients). It answers the question as to what percentage of all patients aged 18-65 receiving acute inpatient care in general psychiatric hospitals could be diverted if there was an enhanced day hospital care model of care. 


\section{Assessment of regional mental health services}

The EDEN study used the European Service Mapping Schedule (ESMS Version 3) to assess characteristics of each regional mental health services system. For the set of mental health services serving the population of a defined geographical catchment area, the ESMS facilitates the following main tasks ${ }^{[31]}$ : (i) compiling an inventory of the mental health services serving the adult mentally ill population of a catchment area, with descriptions of the major characteristics of each service; (ii) delineating and comparing between catchment areas the structure and range of mental health services available, with classification based on the functions of services. Specifically, data on the availability of acute hospital-based residential services (available places ESMS code R2, related to a population of 100,000) and of all residential services (available places ESMS codes R1-13, related to a population of 100,000) were used for this paper.

\section{Statistical issues}

Studying the feasibility rates required a detailed descriptive analysis of the study's recruitment process. Based on the variation of patients' eligibility criteria already reported, four different feasibility estimates were calculated on the basis of "Kluiter's formula". For the third aim of the paper, Spearman's correlation coefficients $\left(r_{s}\right)$ of these estimates and the number of available (acute hospital-based and all) residential services in the five study sites were calculated.

Table 3. Correlation coefficients $\left(\mathrm{r}_{\mathrm{s}}\right)$ of the different feasibility rates and the number of available residential services in the five study sites

\begin{tabular}{lllll}
\hline Feasibility rates & Calculation method A & Calculation method B & Calculation method C & Calculation method D \\
\hline $\begin{array}{l}\text { Acute } \\
\text { hospital-based }\end{array}$ & .7 & .2 & .6 & .1 \\
$\begin{array}{l}\text { residential } \\
\text { services }\end{array}$ & & & & \\
$\begin{array}{l}\text { All residential } \\
\text { services }\end{array}$ & .8 & .7 & .9 & -.1 \\
\hline
\end{tabular}

\section{Results}

Site-specific and overall estimates of feasibility rates of acute day care are given in Table 2. By use of calculation method A site-specific feasibility rates varied from $13.8 \%$ to $25.7 \%$, and overall rate was $17.3 \%$. By use of calculation method B site-specific feasibility rates varied from $17.0 \%$ to $35.5 \%$, and overall rate was $23.9 \%$. By use of calculation method C site-specific feasibility rates varied from $18.8 \%$ to $39.4 \%$, and overall rate was $23.7 \%$. By use of calculation method D site-specific feasibility rates varied from $44.1 \%$ to $79.0 \%$, and overall rate was $67.7 \%$.

The profile of residential services divides the regional mental health care systems of the EDEN-study sites into three types: The Polish and Czech area, both located in big cities, provide a high number of acute and non-acute hospital-based services. This differs completely from the situation in (East-) London as well as in the Slovak region of Michalovce with respect to the capacity for acute admissions. Michalovce also provides a rather high number of inpatient places for rehabilitation and long-stay treatment, whereas East-London has established a significant number of non-hospital based supervised residential facilities which provide a permanent home for persons with mental disabilities. The structure of the residential services in the Dresden area falls between these two poles, where hospital beds have been decreased while more community-based residential facilities have been established.

Spearman's correlation coefficients $\left(\mathrm{r}_{\mathrm{s}}\right)$ of the different feasibility rates and the number of available acute hospital-based services and residential services in the five study sites are given in Table 3. In three out of the four calculation methods higher rates were calculated for sites which demonstrated higher figures of residential services, and thus were less advanced in their process of deinstitutionalization. 


\section{Discussion}

\subsection{Calculation of feasibility rates}

Up to now the calculation of feasibility rates of acute general psychiatric day care was based on a formula developed in the research context of RCTs on this subject. The main point of criticism regarding this formula could be that the resulting figures of feasibility rates significantly depend on the site-specific number of patients excluded from being defined as eligible for acute day care. As demonstrated by the detailed descriptive analysis of the recruitment process performed in the EDEN-study, and by use of the established methods to calculate the lowest (i.e. most inclusive) and highest (i.e. moderately inclusive) estimates of feasibility rates we demonstrated that further restrictions of clinical tasks performed by acute day care would artificially increase the rates, thus challenging the general definition of acute day care in itself.

Thus, the EDEN-study group proposed changes in the calculation methods that would shift the dependence on rates from study definitions to site-specific features of day care units, and towards the clinical responsibilities of the hospitals to which these units might be affiliated.

First, we assumed that one half of the patients refusing to participate in a research project could have engaged in day care, and showed that this definition would increase feasibility estimates by at least $6 \%$.

Second and aiming to establish the most inclusive estimate of feasibility rates, we assumed that all therapeutic (but not strictly diagnostic) tasks and patient groups assigned to inpatient care for general psychiatric patients aged 18 to 65 years could be assigned to acute day care. The consequence for day hospitals would be that they must not only deal with the full spectrum of mental disorders, but also with all degrees of severity and immanent clinical risks of these disorders. In practice, this could be done by associating crisis resolution beds to the day hospital ${ }^{[8,17]}$ or by providing (acute) home treatment ${ }^{[1]}$ by the day hospital staff. If such high-cost organizational parameters were to be established to narrow the gap between inpatient and day care, the site-specific percentage reduction of inpatient admissions in this international study would range from $44.1 \%$ to $79.0 \%$. To realize an even further increase of feasibility rates would force acute day care units to cope with legally-restricted or detained patients (an option given by mental health legislation in several countries ${ }^{[32]}$ ) and provide somatic care equivalent to inpatient standards. This would not only require clarification in many national mental health laws, but would also significantly change currently established clinical practice.

It remains to be seen if the proposed alternative calculation modes might be relevant for health care planning. At least they demonstrate the current lack of methodological consensus in the field on calculating feasibility rates, and the need for further research in this area.

\subsection{Link to the regional availability of residential services}

For each scenario of clinical tasks provided by acute day care units, the percentage reduction of inpatient admissions varied by a factor of nearly 2 across the study sites. Because all sites participating in the EDEN-study strictly and successfully followed all definitions needed for realizing the RCT methodological standard ${ }^{[2,24,25,30]}$, this variation cannot be attributed to any inconsistencies regarding the study-specific definitions of patients' exclusion and inclusion. Results from national surveys on day hospitals lead to the assumption that the importance of the acute care concept for mental health service systems varies significantly, and that this is true on a cross-country (international) as well as on a within-country (regional) level ${ }^{[3,20-23]}$. One explanation regarding characteristics of service configuration which might influence the importance of the acute day care concept seems to be the regional availability of residential services, in particular that of acute hospital-based services. The hypothesis generated from the results of the EDEN study could be that acute day care is a concept more attractive for regional service systems with a high level of institutionalization and less advanced community-orientation. Other important factors have not been assessed in this study, however. For example, other elements of regional service configuration such as the availability of home treatment approaches or geographical realities which might restrict the accessibility of services have not been studied. Further, the position of financial carriers 
regarding the accepted length of stay in (acute) day hospitals needs to be assessed. In addition, the acceptance of such services among those mental health professionals who are responsible for assessing the need of their patients to be hospitalized as well as the culture-specific preference of the patients themselves regarding the treatment setting might play a role.

\subsection{Limitations}

Some specific limitations of the EDEN-study for the issues addressed in this paper should be mentioned. First, the study included only a few heterogeneous study sites recruited without advance consideration of locating areas with comparable socio-demographic and service-related characteristics. Second, five study sites are not sufficient for producing statistically robust calculations. Third, patient-related definitions taken from the viewpoint of academic research might limit generalizability of any service-related conclusions. Fourth, assessment of regional mental health service systems was restricted to compiling an inventory of the mental health services serving the adult mentally ill population of a catchment area, with financial resource constraints limiting the collection of data on the levels of service use for the different types of services.

\section{Conclusions}

In order to define the capacity of day care units as an alternative to acute psychiatric hospital care, mental health care planning must clearly decide on the calculation base for determining feasibility rates in general, and in detail on the site-specific eligibility criteria of patients to be treated in these facilities. Guided by such decisions, treatment concepts and professional qualifications of the staff in these facilities need to be adapted. Effectiveness and cost-effectiveness studies in these facilities assessing patients with higher clinical and economic risks are urgently needed. If not guided by data indicating how a change of the severity mix of patients would change the achievable cost savings, health care policies will not consider promoting an increasing use of day hospitals. Further, effects of (regional) mental health service configuration on the feasibility of acute day care need to be explored in more detail. The hypothesis that acute day care is a concept more attractive for regional service systems with a high level of institutionalization and less advanced community-orientation should be assessed in much more detail, and further factors influencing this concept should be identified. This would need large mental health services research projects, at least on a national level, which systematically collect data by use of standardized measures describing socio-demographic and service-specific characteristics in clearly defined geographical areas, and link such data in statistical multi-level approaches with characteristics of patients treated in the services ${ }^{[33]}$.

\section{Competing interests}

The authors declare that they have no competing interests.

\section{Authors' contributions}

TK led on the analysis and interpretation reported in this paper and took overall responsibility for its writing. Further, he was the principal investigator on the grant of the European Commission (ref: QLG4-CT-2000-01700) and supervised the overall study completion. JR, SP, AK, and PN contributed to the study design and managed local study implementation in the different countries. AH and MS contributed to local study implementation and substantially revised earlier versions of the paper. All authors contributed to and approved the final version of the paper. All authors had full access to all of the data (including statistical reports and tables) in the study and can take responsibility for the integrity of the data and the accuracy of the data analysis.

\section{Acknowledgements}

The multi-site research project (Acronym: EDEN-study) "Psychiatric day hospital treatment: An alternative to inpatient treatment, being cost-effective and minimizing post-treatment needs for care? An evaluative study in European countries with different care systems" was funded by the European Commission (Quality of Life and Management of Living 
Resources Programme, contract no. QLG4-CT-2000-01700). Additional national grants supporting the project were provided by Roland-Ernst-Stiftung für Gesundheitswesen and the Faculty of Medicine at the Dresden University of Technology, the National Health Service Executive Organization and Management Programme, the Polish National Committee of Scientific Affairs, and the Slovak Ministry of Education. Pfizer Pharmaceutical Company supported travel and accommodation for EDEN project meetings. The authors gratefully acknowledge the assistance in text editing from Charlene Reiss.

\section{References}

[1] Eikelmann B, Becker T, Rössler W, Kallert TW: Versorgungsstrukturen in der Psychiatrie. In Psychiatrie und Psychotherapie. 4. Auflage. Edited by Möller HJ, Laux G, Kapfhammer HP. Berlin: Springer. 2011; 1143-1175.

[2] Kallert TW, Priebe S, McCabe R, Kiejna A, Rymaszewska J, Nawka P, Očvár L, Raboch J, Stárková-Kališová L, Koch R, Schützwohl M: Are day hospitals effective for acutely ill psychiatric patients? A multi-center European randomized controlled trial. J Clin Psychiatry. 2007; 68: 278-287. PMid:17335327 http://dx.doi.org/10.4088/JCP.v68n0214

[3] Kallert TW, Schützwohl M, Glöckner M, Priebe S, Briscoe J, Rymaszewska J, Adamowski T, Nawka P, Reguliova H, Raboch J, Howardova A: A comparison of psychiatric day hospitals in five European countries: implications of their diversity for day hospital research. Soc Psychiatry Psychiat Epidemiol. 2004; 39: 777-788. PMid:15669658

[4] Creed F, Black D, Anthony P, Osborn M, Thomas P, Tomenson B: Randomised controlled trial of day patient versus inpatient psychiatric treatment. BMJ. 1990; 300: 1033-1037. PMid:2188696 http://dx.doi.org/10.1136/bmj.300.6731.1033

[5] Creed F, Mbaya P, Lancashire S, Tomenson B, Williams B, Holme S: Cost effectiveness of day and inpatient psychiatric treatment. BMJ. 1997; 314: 1381-1385. PMid:9161310 http://dx.doi.org/10.1136/bmj.314.7091.1381

[6] Dick P, Cameron L, Cohen D, Barlow M, Ince A: Day and full time psychiatric treatment: a controlled comparison. Br J Psychiatry. 1985; 147: 246-249. PMid:4063589 http://dx.doi.org/10.1192/bjp.147.3.246

[7] Wiersma D, Kluiter F, Nienhuis F, Ruphan M, Giel R: Costs and benefits of day treatment with community care of affective and schizophrenic disorders. Br J Psychiatry. 1995; 166: 52-59.

[8] Sledge WH, Tebes J, Wolff N, Helminiak TW: Day hospital/crisis respite versus inpatient care, part II: service utilization and costs. Am J Psychiatry. 1996; 153: 1074-1083. PMid:8678177

[9] Kallert TW, Schönherr R, Schnippa S, Matthes C, Glöckner M, Schützwohl.M: Direct costs of acute day hospital care: results from a randomized controlled trial (in German). Psychiat Prax. 2005; 32: 132-141. PMid:15818529

http://dx.doi.org/10.1055/s-2004-834712

[10] Priebe S, Jones G, McCabe R, Briscoe J, Wright D: Effectiveness and costs of acute day hospital treatment as compared with conventional in-patient care: Randomised controlled trial. Br J Psychiatry. 2006; 188: 243-249. PMid:16507966 http://dx.doi.org/10.1192/bjp.188.3.243

[11] Marshall M, Crowther R, Almaraz-Serrano A Creed F, Sledge W, Kluiter H, Roberts C, Hill E, Wiersma D: Marshall M, Crowther R, Almaraz-Serrano AM, Sledge WH, Kluiter H, Roberts C, Hill E, Wiersma D: Day hospital versus admission for acute psychiatric disorders. Cochrane Database of Systematic Reviews. 2003, Issue 1. Art. No.: CD004026. http://dx.doi.org/10.1002/14651858.CD004026

[12] Zwerling J, Wilder JF: An evaluation of the applicability of the day hospital in the treatment of acutely disturbed patients. Isr Ann Psychiatry Related Disciplines. 1964; 2: 162-185.

[13] Kris EB: Day hospitals. Curr Ther Res. 1965; 7: 320-323. PMid:14286214

[14] Herz MI, Endicott J, Spitzer RL, Mesnikoff A: Day versus in-patient hospitalization: a controlled study. Am J Psychiatry. 1971; 127: 1371-1382. PMid:5549929

[15] Schene AH, van Wijngaarden B, Poelijoe NW, Gersons BPR: The Utrecht comparative study on psychiatric day treatment and in-patient treatment. Acta Psychiatr Scand. 1993; 87: 427-436. PMid:8356895 http://dx.doi.org/10.1111/j.1600-0447.1993.tb03400.x

[16] Nienhuis FJ, Giel R, Kluiter H, Rüphan M, Wiersma D: Efficacy of psychiatric day treatment. Course and outcome of psychiatric disorders in a randomised trial. Eur Arch Psychiatry Clin Neurosci. 1994; 244: 73-80. PMid:7948057 http://dx.doi.org/10.1007/BF02193522

[17] Sledge WH, Tebes J, Rakfeldt J, Davidson L, Lyons L, Druss B: Day hospital/crisis respite care versus inpatient care, Part I: Clinical outcomes. Am J Psychiatry. 1996; 153: 1065-1073. PMid:8678176

[18] American Academy of Child \& Adolescent Psychiatry, American Psychiatric Association: Criteria for short-term treatment of acute psychiatric illness. Washington DC; 1996. 
[19] Schene AH: Partial hospitalization. In Textbook of community psychiatry. Edited by Thornicroft G, Szmukler G. Oxford: Oxford University Press. 2001; 283-289.

[20] Kallert TW, Schützwohl M, Matthes C: Current structural and procedural quality markers of psychiatric day hospitals in Germany (in German). Psychiat Prax. 2003; 30: 72-82. PMid:12601596 http://dx.doi.org/10.1055/s-2003-37442

[21] Briscoe J, McCabe R, Kallert TW, Priebe S: A national survey of psychiatric day hospitals in England. Psychiat Bull. 2004; 28: 160-163. http://dx.doi.org/10.1192/pb.28.5.160

[22] Kitzlerova E, Raboch J, Pec 0, Starkova L, Bakova N, Sekot M, Howardova A, Peichlova J: Survey of day hospitals in Czech Republic (in Czech). Czech and Slovak Psychiatry. 2003; 99: 299-305.

[23] Rymaszewska J, Kiejna A, Adamowski T, Szurminska M, Hadrys T, Malyszczak K, Trypka E, Zajac J, Jarosz J: Characteristics of day hospitals in Poland - results of questionnaire survey (in Polish). Psychiatr Pol. 2003; 37: 1037-1048. PMid:14727375

[24] Kallert TW, Schützwohl M, Kiejna A, Nawka P, Priebe S, Raboch J: Efficacy of psychiatric day hospital treatment: Review of research findings and design of a European multi-centre study. Archives of Psychiatry and Psychotherapy. 2002; 2 : 55-71.

[25] Kallert TW, Schützwohl M: Randomised controlled trials in mental health services research: practical problems of implementation (in German). Fortschr Neurol Psychiat. 2002; 70: 647-656. PMid:12459946 http://dx.doi.org/10.1055/s-2002-35856

[26] Schützwohl M, Jarosz-Nowak J, Briscoe J, Szajowski K, Kallert TW, EDEN-study group: Inter-rater reliability of the Brief Psychiatric Rating Scale (BPRS 4.0) and the Groningen Social Disabilities Schedule (GSDS-II) in a European multi-site randomised controlled trial on the effectiveness of psychiatric day hospitals. Int J Meth Psych Res. 2003; 12: 197-207. http://dx.doi.org/10.1002/mpr.157

[27] Kallert TW, Priebe S, Schützwohl M, Glöckner M, Briscoe J, EDEN-study group: The role of acute day hospital treatment for mental health care: Research context and practical problems of carrying out the international multi-centre EDEN-study. In Public Health in Europe. Edited by Kirch W. Berlin: Springer. 2004; 153-171. http://dx.doi.org/10.1007/978-3-642-18826-8_18

[28] Eichler T, Schützwohl M, Priebe S, Wright D, Adamowski T, Rymaszewska J, Nawka P, Očvár L, Kitzlerova E, Raboch J, Kallert TW: Losses to follow-up in longitudinal psychiatric research. Epidemiologia e Psichiatria Sociale. 2008; 17: $138-147$. PMid:18589630

[29] Kluiter H, Giel R, Nienhuis FJ, Rüphan M, Wiersma D: Predicting feasibility of day treatment for unselected patients referred for in-patient psychiatric treatment: results of a randomized trial. Am J Psychiatry. 1992; 149: 1199-1205. PMid:1503133

[30] Altman DG, Schulz KF, Moher D, Egger M, Davidoff F, Elbourne D, Gotzsche PC, Lang T, CONSORT GROUP: The revised CONSORT statement for reporting randomized trials: explanation and elaboration. Ann Intern Med. 2001; 134: 663-694. PMid:11304107

[31] Johnson S; Kuhlmann R, and the EPCAT Group: The European Service Mapping Schedule [ESMS]. Version 3 - February 1997. University College London Medical School, Department of Psychiatry and Behavioural Sciences, London. 1997.

[32] Kallert TW, Torres-González F (Eds.): Legislation on Coercive Mental Health Care in Europe. Legal Documents and Comparative Assessment of Twelve European Countries. Berlin Bern Bruxelles Frankfurt/M New York Oxford Wien: Peter Lang Europäischer Verlag der Wissenschaften. 2006.

[33] Pirkola S, Sund S, Sailas E, Wahlbeck K: Community mental-health services and suicide rate in Finland: a nationwide small-area analysis. Lancet. 2009; 373: 147-153. http://dx.doi.org/10.1016/S0140-6736(08)61848-6 